\title{
The Positive Affect of Leadership on Employee Performance and Its Impact on Improving Workplace Environment in Addition to Organizational Culture
}

\author{
Kemal M. Surji PhD, RRT, HA \\ LFU-BMU University, Hawler Medical University \\ *Email: ksurjihiex@yahoo.com
}

\begin{abstract}
Today's organizations are in need of strong leadership in dealing with many factors of organizational culture including employee performance and satisfaction, work environment and achievement rewards. Therefore, if any of these factors are overlooked by the leadership team, the entire organization will be less effective. The intention of this research is to examine the leadership's influence on employee performance and improving workplace environment in local companies. The researcher conducts survey of neighboring businesses to determine the leadership effectiveness and to identify the area of organizational weakness. The results of the survey indicate that local organizations could benefit from a better leadership practice and well develop employee recognition plan and team work in order to achieve organizational mission with a gratifying culture. The aim of the study was to identify the definite intentions of leadership, its influential effects on organizational culture and possible suggestions that could be supportive to the industries for their efficiency, productivity and performance.
\end{abstract}

Keywords: Leadership, Employee Performance, Organizational Culture, Rewards.

DOI: $10.7176 / \mathrm{EJBM} / 6-25-2014-02$

\section{Introduction}

This study is being conducted to determine the current status of the organizational leadership regarding employee performance, recognition and organizational culture; also possibility of any modification to the existing condition. There are many prominent aspects that need to be considered such as leadership, trust, incentive and appreciation, as well as feelings of safety and security. When these elements are threatened, employees begin to lose morale resulting in decrease performance and satisfaction rates; therefore, causing an inefficient and ineffective organization.

Influence of leadership on employee productivity and culture within an organization is very essential, playing a great role in whether or not the organization is a fun and safe place to work. Although leaders may be communicating and promoting the organizational vision to subordinates, however, they are not capable in getting their acknowledgement of the vision; therefore, it isn't possible to influence their work behavior and attitudes. When there are good relations between the leader and employees, there will be contributions to team communication and solidarity, and encouragement of subordinates to accomplish the mission and objectives assigned by the organization, which in turn enhances performance and job satisfaction.

The local organizations under study are employing more than 30 employees and management team of a top manager and several line managers. In recent times, these particular organizations have experienced many employee turnovers. Factors associated with this turnover most often relates to inappropriate leadership behavior resulting in sense of mistrust, and lack of appreciation. Due to the nature of the issues, there has been a significant amount of mistrust, anxiety, and fear on the part of the employees and also a lack of employee performance and job satisfaction.

These inappropriate factors have created a significant damage to the organizational culture and leadership reputation. Employees in any organization are expected to feel that they can be trusted and have trust in the leadership; however, in these organizations, that element is gravely missing. If the concerns are not discussed and some changes made, the companies will undergo greater employee turnover, which will raise costs for recruiting, hiring and training new employees and cause ineffective organizational performance and productivity.

\section{Statement of Problem}

Weak Organizational leadership has created grave damage to organizational culture and employee performance; mistrust and lack of reward and recognition program fabricated ineffective environment and decrease organizational performance.

\section{Purpose of the Study}

The aim of this research is to examine, based on the survey conducted of local businesses, the leadership's effect on employee performance and improving workplace environment in local companies. 


\section{Research Objectives}

1. To determine the affect of leadership on employee performance.

2. To evaluate the effect of leadership on organization's environment and culture.

3. To verify the essential factors of the organization's culture on an employee's performance.

4. To conclude to what degree the leadership impact's employee performance and satisfaction.

5. To find out if a reward and recognition program would enhance employee performance.

\section{Importance of the Study}

The impact of this study is to verify the scope that leadership team has on the workforce performance within the organization and its workplace environment also the factors contributing to the overall organizational culture. Based on the study conducted of local Companies, those elements will be recognized and will determine their association to the employees involved.

\section{Review of Related Literature}

The important elements in determining well performing organizations with satisfied workforce are summarized as leadership, employee performance, recognition, reward, and organizational environment or culture. There has been tremendous attention to these factors by many writers and consultants in reiterating these factors as the driving force of contributing to employee performance and the environment within the organization. This literature reviews are the compilation of ideas from different resources discussing those elements and components that contribute to employee performance, workforce satisfaction and organization's culture.

\section{Leadership}

Leadership qualities that influence workforce performance include the ability to create vision, comprehend organizational culture, concentrate on performance improvement, and promote innovation.

Leadership:" ... an observable set of skills and abilities that are useful whether one is in the executive suite or on the front line ... And any skill can be reinforced, sharpened, and improved, given the enthusiasm and aspiration, providing practice and criticism, and the role models and coaching" (Kouzes \& Posner, 2002 p. 386).

Great leaders grant opportunities for workforce to exploit their aptitudes and strengths, and support them every step of the way. Leaders encourage vastness, not for their own personal gain, but for the betterment of the citizens they lead. Jim Collins (2001) refers to these individuals as "Level 5 leaders." although not every leader has all five levels of leadership, in this particular level leader has all of the qualities of other levels listed as follow: Level 1 - extremely competent person, Level 2 - contributing team member, Level 3 - capable manager, and Level 4 - an effective leader (p. 20).

Level 5 leaders direct their ego requirements away from themselves and into the superior ambition of structuring a better business. It does not mean that Level 5 leaders have no personality or self-interest. In fact, they are exceedingly determined - but their aspiration is first and foremost for the organization, not themselves (Collins 2001 p 21).

Leadership qualities can be found in anyone and leaders can appear from anywhere, however, there are definite practices and obligations that make people leaders. According to the authors, Jim Kouzes and Barry Posner (2002), five practices for exemplary leadership are identified.

Entrenched within these five practices are ten commitments that serve as a guide for how leaders accomplish astonishing performance in an organization.

The five practices and corresponding commitments are as follows:

1. Model the Way

Find your vote by clarifying your own morals

Set the examples by aligning actions with shared values

2. Inspire a Shared Vision

a. Envision the future by imagining exciting and ennobling possibilities

b. Enlist others in a common vision by appealing to shared aspirations

3. Challenge the process

a. Search for opportunities by seeking novel ways to modify, cultivate, and enhance

b. Experiment and take risks by constantly generating small wins and learning from mistakes

4. Enable others to act

a. Foster collaboration by promoting cooperative goals and building trust

b. Strengthen others by sharing power and discretion

5. Encourage the Heart

a. Recognize contributions by showing appreciation for individual excellence

b. Celebrate the values and victories by creating a spirit of community (p. 22). 
Leaders play a significant part in influencing employee performance and an organization's culture; in fact, leaders are one of the most essential elements of an organization. In a survey carried out by the Gallup Organization (Buckingham \& Coffman, 2005), a very significant discovery was made ... the manager not pay, benefits, bonus, or a compelling company leader was the decisive actor in building a sturdy work environment. The manager was the key. Eventually, workers may join organizations for various reasons such as great benefits; flexible schedule, great pay, and so on. However, the length of time the employees stays and how productive they might be is determined by her relationship with her immediate supervisors. If the manager sets clear expectations, knows the employees, trusts them, and invests in them, the employees can pardon the lack of enticement. However, if the association between manager and employee is broken, no amount of bonus or benefits will encourage workers to stay: It is better to work for a great manager in an old-fashioned company than for a terrible manager in a company offering an enlightened, employee-focused culture (Buckingham, \& Coffman, 2005 p. 28).

\section{Organizational Culture}

Organizational culture is a type of combined interpretative method shared by the constituents of an organization, as they assign meaning to events, people, and proceedings within the organization in a comparable way and care for them accordingly (Schein, 2004; Alvesson, 2002; Martin, 2002). The character of diverse components of management and organization, such as strategic plan formation, leadership approach, organizational wisdom, method of rewards, and motivation, materialize exactly from the way in which employees and management understand organizational reality and behave in it (Wilderom, Glunk \& Maslowski, 2000).

An organization's culture is a major characteristic of an organization. Additionally, Environment and culture of a business consists of several aspects including but not limited to leadership approach, professional growth, communication, life and work balance, employee satisfaction, reward program, and organizational performance. Even though it is complicated to define culture, it is a sensitive matter that can be felt by the workforce, the leadership, and the customers of the organization. Therefore, When any of the elements of the culture are neglected, the reflection can be manifested throughout the organization - productivity decreases, lowers the profits, and employee morale tumbles.

The three levels of culture is defined by Schein (1999) the most noticeable of which is artifacts, the observable level of culture that consists of what is seen, heard, and felt in a group. This level includes things such as the physical environment, language, technology, interactions between members, manner of dress, ritual, ceremonies, and published principles, visions, and missions. Schein stated that culture is clear and has an instant touching impact. However, the behaviors of organizational members are not truly understood (1999 p. 16-17).

At the second level are espoused values. Although it is not actually observable, but values largely determine behavior. When a group of people gather certain folks will make propositions about what is right or wrong, and what will and won't work, but those suggestions are only proposals until the group acts as a team and authenticates those suggestions as success. Afterward the group begins to create its shared values. The beliefs and values at this level are often what dictate the behavior in the first level.

At the deepest level of an organization's culture are fundamental assumptions. This level comprises the unconscious, taken for granted beliefs, views, values, and feelings that were formed and have since been shared by the members of the culture. Anyone new to the group assumes that the leaders of the organization have been successful while operating under these assumptions and therefore must be right (Schein, 1999).

Every faction, or culture, goes through a period of alteration from its creation until its establishment. The processes included in this period are referred to as "forming", "storming", "norming", and "performing" Tuckman (1965).

In "forming," members of the group are new to one another and therefore a bit timid about sharing any real feeling or thoughts and stick mostly to general information. Even items such as the objectives of the group are rarely discussed. Due to the nature of people, cliques are starting to form but at this point they do not have much influence on the rest of the team. A few people are more talkative than others, but are still only participating in general topic areas.

In "storming," group members are becoming more familiar with each other and are struggling to be heard. There is a lot of differences about the objectives or goals of the group and how to achieve them; individuals, as well as cliques, are trying to have their ideas heard and are trying to persuade others in order to gain supremacy and admiration, others are sitting back and waiting for things to settle down. Conflict is very high during this process.

In "norming," group members are starting to feel more comfortable with each other and are more interested in teamwork to achieve objectives and goals together. Most people are open to new ideas and are sharing information with one another in order to gain understanding. Cliques are dissolving and people are not simply trying to influence each other, so there is less conflict within the group.

Finally, in "performing," the group is meeting their objectives and are working together, seeking out 
other people's opinions and offering their own. They work hard to see all sides of an issue and view disagreements as a way to do just that (Tuckman, 1965 p. 396).

After the establishment of a culture within an organization, possibility of change is roughly impracticable. Change becomes a way of life for all existing and new members; therefore, initiating change takes either a major predicament, or potential for disaster, or a very influential and forward thinking leader. He/she must possess various skills in order to convince the others that change is necessary including the ability to see the organization from the external view point, the power and leadership of someone successful, the ability to create and convey a new vision and strategies necessary for change, the capability to model the desired behavior, and a talent for motivating and encouraging others (Kotter \& Heskett, 1992).

\section{Employee Performance}

The extent of an attainment to which an employee's fulfill the organizational mission at place of work is called performance (Cascio, 2006). Performance has been perceived in a different way by different researchers, but most of the scholars relate performance with measurement of transactional efficiency and effectiveness towards organizational goals (Stannack, 1996; Barney, 1991).

.The job of an employee is build up by degree of achievement of a particular target or mission that defines boundaries of performance (Cascio, 2006). Some canvassers have identified dissimilar notion, approaches and values of performance as it assists in dimension of input and output efficiency measures that lead to transactional relationship. (Stannack, 1996)

For decades, corporations have been talking about their assets and what makes their companies profitable. For a lot of companies "assets" used to mean materials such as wood, steel, computer components, etc; and for some, it still does. Today, the term "assets" often refers to something even greater called people. Human capital are what run business today, people are what generate the sales, people are what build and develop products; people are who decide if they want to be an "asset" or not. Turnover in business is higher than it's ever been and in a country where people used to stay in one job for the entirety of their lives the fact that the average worker today only spends about three and a half years in the same job is a hefty bite to gulp. Organizations used to spend very little time recruiting, hiring, and retaining; now they have minute options. Companies must find a way to keep the talented people employed within their organizations; therefore, the development of incentive programs (monetary or otherwise), casual dress initiatives, flexible scheduling, work teams, and so on may possibly enhance retention. However, monetary efforts such as raises or bonuses rarely make much of an impact on employee performance beyond the moment. (Gostick \& Elton, 2001).

The other programs, such as flexible scheduling are not always obtainable due to the nature of the business or the specialization of the job. And casual dress, though comfortable and nice as a change of pace, does not often make a significant impact on an employee's cheerfulness within the overall position.

\section{Employee Recognition and Rewards}

The majority of companies to this day fail to notice a very powerful tool in their arsenal called recognition. Furthermore, there is a confirmed association between workplace satisfaction and employee appreciation, as recognition being the most valuable way to promote corporate aim, thereby creating memorable appreciation experiences one can tie an employee to the organization (Gostick \& Elton, 2001 p. 18-19).

Recognition presented in many ways; the dilemma is that majority of managers assume they are recognizing their staff when they really are not doing so. Incentives, bonuses, and benefit are not forms of recognition alone; they only become recognition when they are awarded for a job well done. In order to count as recognition, the message must be clear; managers need to enlighten the reason someone is being awarded a plaque or other form of rewards for example. Without rationalization for why and a foundation for how, employees do not comprehend, and then the effort at recognition becomes a washed out opportunity.

Leigh Branham identifies feeling undervalued and unrecognized as one of the seven reasons employees leave organizations. The desire for recognition comes from the basic human need to feel a feeling of worth. sensing confident that if an employee works hard, do the best job, show dedication, and make significant contributions to the company, then he/she will be recognized and rewarded accordingly( 2005, p. 20). On the other hand, this is not always true. Although numerous studies have been conducted to show the importance of recognition on an employee's satisfaction, managers still are reluctant, and continue to fail, to recognize their employees. Sometimes managers have worked for others who's philosophy was that if they didn't hear anything, it meant they were doing their jobs right, and also that no one should be recognized for doing a job they were hired, and get paid, to do.

A number of managers plainly do not pay adequate attention to their workers to know how well and precise they carry out their tasks.

Maybe they do not know enough about the employee's job to determine whether they are performing well or not, and therefore cannot recognize. Other managers are afraid that employees will think they are 
insincere in their efforts at recognition or that they will unintentionally "play favorites" recognizing some while forgetting others (Branham, 2005).

When done right, recognition can enhance communication and trust, and improve employee selfesteem. According to Gostick \& Elton, recognition and employee appreciation is a powerful tool that can spread throughout the organization expeditiously; therefore, creating such culture can enhance employee retention as they realize their hard work will be acknowledged and rewarded (2001 p. 14).

\section{Conclusion}

Literature review has identified various resources that concentrate on the key elements in an organization, explicitly culture, leadership, as well as employee recognition and performance. Such resources have revealed that each piece is vital to an organization and the people within the organization. A good deal of the discussion and recommendations made by the researcher will be based upon the review of these resources.

\section{Research Methods}

The region is new to many organizations foreign and domestic as it is growing and demand for skill labor is on the rise, however, retaining good staff has been challenging for numerous companies in the region due to various situations including, lack of leadership and leadership changes, improper behavior, lack of pleasant work environment and organizational culture. Thus, it has encouraged the researcher to assess the strength of the leadership and cultures of a few companies in the immediate area.

The researcher conducted a climate assessment survey of the four well known companies in the area. A climate assessment method was preferred in order to gain an understanding of the organization's culture and how it is professed by those surveyed. In doing so, an image of the organization will develop which will present answers to the stated objectives; the results of which will lead to findings and be the basis for all recommendations made by the researcher.

Participants were chosen by random sample of a population from the selected area companies. Survey questionnaire, developed by researcher, were mailed to participants to be completed and return to sender. Anonymity was assured and preserved during the course of the study.

After the surveys were returned, the data was analyzed and recommendations made based upon the findings.

\section{Population Sample}

The number of employees within each organization varies depending on the size and volume of the company. Managers were not surveyed only assistant managers along with regular staff were included in the process. In total, there were eighty-two survey questionnaires sent out and thirty-three were returned completed.

Of the thirty-three participants that returned the survey 10 had been working for the company for longer than ten years, two had been there more than four years but less than ten, thirteen had been with the company between one and three years, and eight had been there less than a year.

With regard to age of the participants, the majority fell into two categories - ages 18-25 and 40-60; twelve for each age group. Eight of the participants were between the ages of 26 and 40, and only one participant was older than 60. Most of the contributors, twenty-four to be precise, were also rated at full time status, meaning they worked in excess of thirty-two hours in a given week. Three worked between twenty-one and thirty-one, five worked between eleven and twenty hours, and only one working less than ten hours per week. Finally, of the thirty-three participants, nine were students.

Population sample

\begin{tabular}{|c|c|c|c|c|c|c|c|c|c|c|c|c|}
\hline \multicolumn{4}{|c|}{$\begin{array}{c}\text { Time with the company } \\
\text { (years) }\end{array}$} & \multicolumn{4}{|c|}{ Age } & \multicolumn{4}{|c|}{ Work hours per week } & $\begin{array}{l}\text { Any other } \\
\text { status }\end{array}$ \\
\hline$>10$ & $4-9$ & $1-3$ & $<1$ & $18-25$ & $26-39$ & $40-60$ & $>60$ & $32-40$ & $21-31$ & $11-20$ & $<10$ & \\
\hline 10 & 2 & 13 & 8 & 12 & 8 & 12 & 1 & 24 & 3 & 5 & 1 & 9 students \\
\hline
\end{tabular}

\section{Demographic Page}

Dear employees,

I appreciate your partaking in this study. The focus of this survey is on the leadership and culture of the place in which you work and its influence on your performance within your job. All information presented by you will be stringently classified and will be used for data collection purposes only. Please answer the following background information before proceeding to the rest of the survey. Please use a pen to complete the questionnaire and circle the answer that best describes you.

1 . What is your age?
a. $16-25$
b. $26-40$
c. $41-60$
d. 61 and over 
2. How long have you worked at your present job?
a. Less than a year
b. 1-3 years
c. 4- 10 years
d. Longer than 10 years

3. How many hours a week do you work?
a. $0-10$
b. 11-20
c. 21-31
d. $32-40+$

4. Are you a student?
a. Yes
b. No

\section{Instrumentation}

A Climate Assessment was chosen as the means of data compilation. The examiner formed and developed the survey questionnaire indicated below that would be used in the Climate Assessment. The survey used was developed to measure several different aspects of the cultures within the four companies including: individual Commitment and Performance, Workplace Environment, Recognition and Satisfaction, and the Relationship with Leadership. The statements within each of these sections were to be answered using a five-point Likert scale ranging from strongly disagree to strongly agree.

Also included in the assessment was a cover page intended to collect the demographic information discussed above. An open-ended statement at the bottom of this cover page directed participants to make any additional comments if they chose to do so.

\section{Leadership, Corporate Culture and Performance Survey}

This section of the study will consist of questions related to your job and the place of work. The researcher appreciates your response to each question as it applies to you, based on the following scale:
$\mathrm{SD}=$ Strongly Disagree
A $=$ Agree
$\mathrm{D}=$ Disagree
$\mathrm{SA}=$ Strongly Agree
$\mathrm{N} / \mathrm{u}=$ Neutral/Undecided

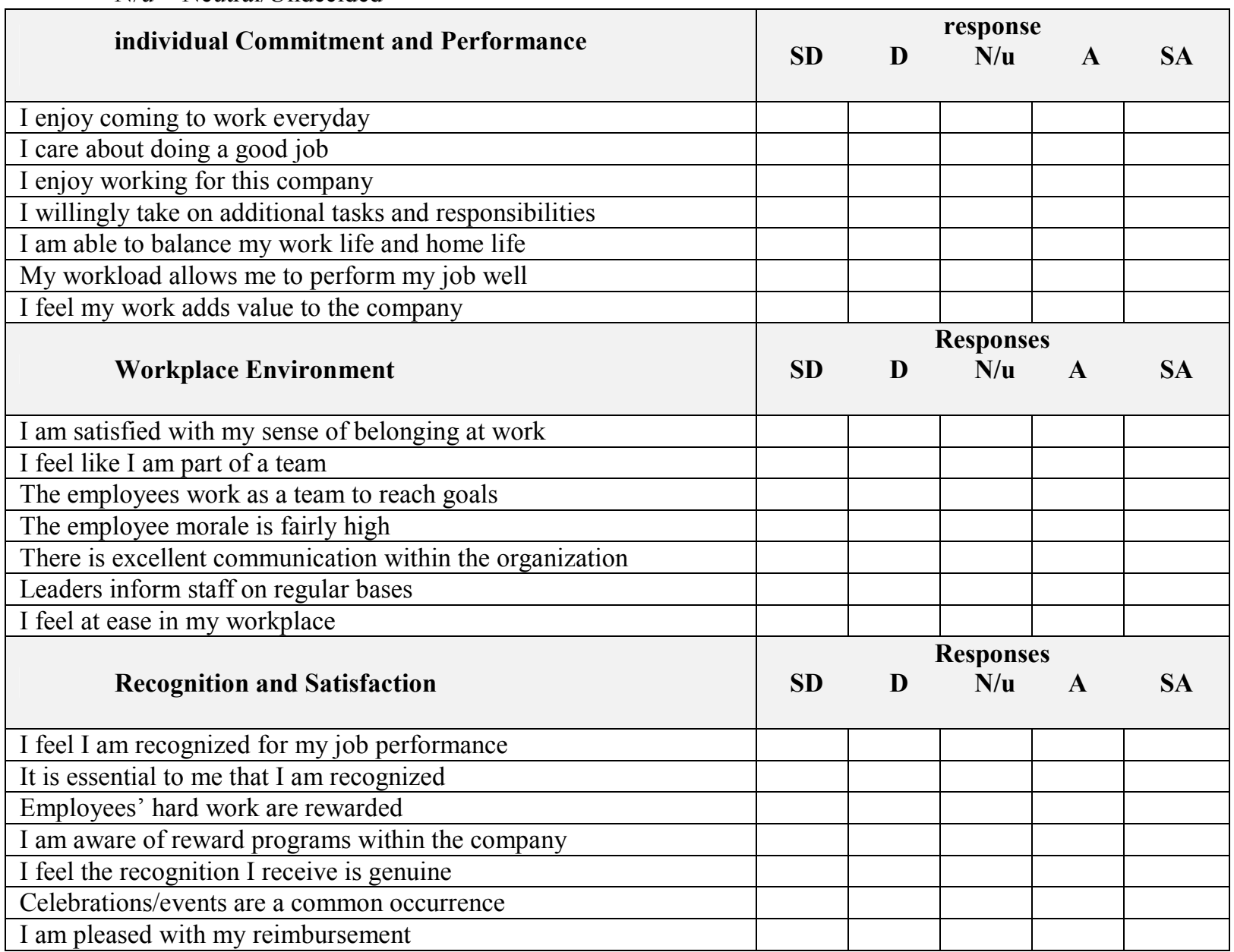




\begin{tabular}{|c|c|c|c|c|c|}
\hline \multirow[b]{2}{*}{ Relationship with Leadership } & \multicolumn{5}{|c|}{ Responses } \\
\hline & SD & D & $\mathbf{N} / \mathbf{u}$ & $\mathbf{A}$ & SA \\
\hline I feel leadership team cares about me as an individual & & & & & \\
\hline leaders are supportive of my performance & & & & & \\
\hline My ideas/suggestions are taken seriously & & & & & \\
\hline leaders treat employees with dignity and respect & & & & & \\
\hline Management regards each employee as important & & & & & \\
\hline Leadership team has the respect of the employees & & & & & \\
\hline Leadership team can be trusted & & & & & \\
\hline I feel leaders would make personal sacrifices for the team & & & & & \\
\hline Management includes themselves as part of the overall team & & & & & \\
\hline Management works as hard as they expect employees to & & & & & \\
\hline $\begin{array}{l}\text { I feel comfortable approaching leadership team with } \\
\text { concerns/questions }\end{array}$ & & & & & \\
\hline Management works as a team to reach the same goals & & & & & \\
\hline
\end{tabular}

\section{Data Collection}

In order to collect the data, the surveys were sent to each of the employees randomly. A confidentiality form was included with the survey explaining the results of the survey and identity of participants would be kept strictly confidential; moreover, the information will be used for the purpose of data collection only.

\section{Data Analysis}

A quantitative analysis method was used in compiling the results from the survey. The questions from the climate survey were used to determine how the organization was performing in regards to the interaction between the employees, including management. The sections of the survey were each directed at gaining specific knowledge in a certain area affecting the employees and their consequent performance and satisfaction.

\section{Limitations}

The participation in the study was entirely voluntary; therefore, not all employees who received surveys completed or returned them. Although anonymity was guaranteed and confidentiality maintained throughout the process, some may not have felt secure that their responses would not be reported to upper management levels, and therefore did not complete a survey or answer as honestly as expected. There were a total of eighty-two surveys sent out, and thirty-three were completed and returned to the examiner.

The study outcomes are restricted to the few local companies based in the region; therefore an overall determination cannot be made about all the organizations in the region. Furthermore, because only those few companies were included in the study, the findings of the survey, and subsequent recommendations, are based solely on those employees.

\section{Findings}

This study is being conducted to determine the current status of the organizational leadership regarding employee performance and recognition and organizational culture; and possibility of any modification to the existing condition. There are many prominent aspects that need to be considered such as leadership, trust, incentive and appreciation, with feelings of safety and security. Meanwhile, if these elements are threatened, employees begin to lose morale resulting in decrease performance and satisfaction rates; therefore, causing an inefficient and ineffective organization.

The survey questionnaire, developed and distributed by the examiner, was created to determine which of those elements could be recognized as the most significant; additionally, things that can be done to re-establish the culture to one that is gratifying and effective, if possible.

The results shown in the tables below reflect the responses to each question for each section of the survey. The results are given as actual numbers.

The answers are based on the Likert scale used for the study as described earlier and are as follows SD-strongly disagree, D-disagree, N/u neutral/undecided, A-agree, and SA-strongly agree.

\section{1- Individual Commitment and Performance}

The primary division in the climate assessment analysis was individual commitment and performance. This part was intended to determine employees' feeling about their jobs on a basic level, nothing excessively complicated, simple questions about how they felt to be in the position they occupy. 
Table-1- Individual Commitment and Performance

\begin{tabular}{|c|c|c|c|c|c|}
\hline \multirow{2}{*}{ Individual Commitment and Performance } & \multicolumn{5}{|c|}{ Responses } \\
\hline & SD & D & & $\mathbf{A}$ & $\mathbf{S A}$ \\
\hline I enjoy coming to work everyday & 1 & - & 2 & 22 & 7 \\
\hline I care about doing a good job & - & - & - & 7 & 26 \\
\hline I enjoy working for this company & 1 & 1 & 1 & 17 & 13 \\
\hline I willingly take on additional tasks and responsibilities & - & - & 3 & 12 & 18 \\
\hline I am able to balance my work life and home life & 1 & 4 & 3 & 14 & 11 \\
\hline My workload allows me to perform my job well & 1 & 2 & 7 & 21 & 2 \\
\hline I feel my work adds value to the company & - & - & 5 & 17 & 11 \\
\hline
\end{tabular}

Chart-1- individual Commitment and Performance

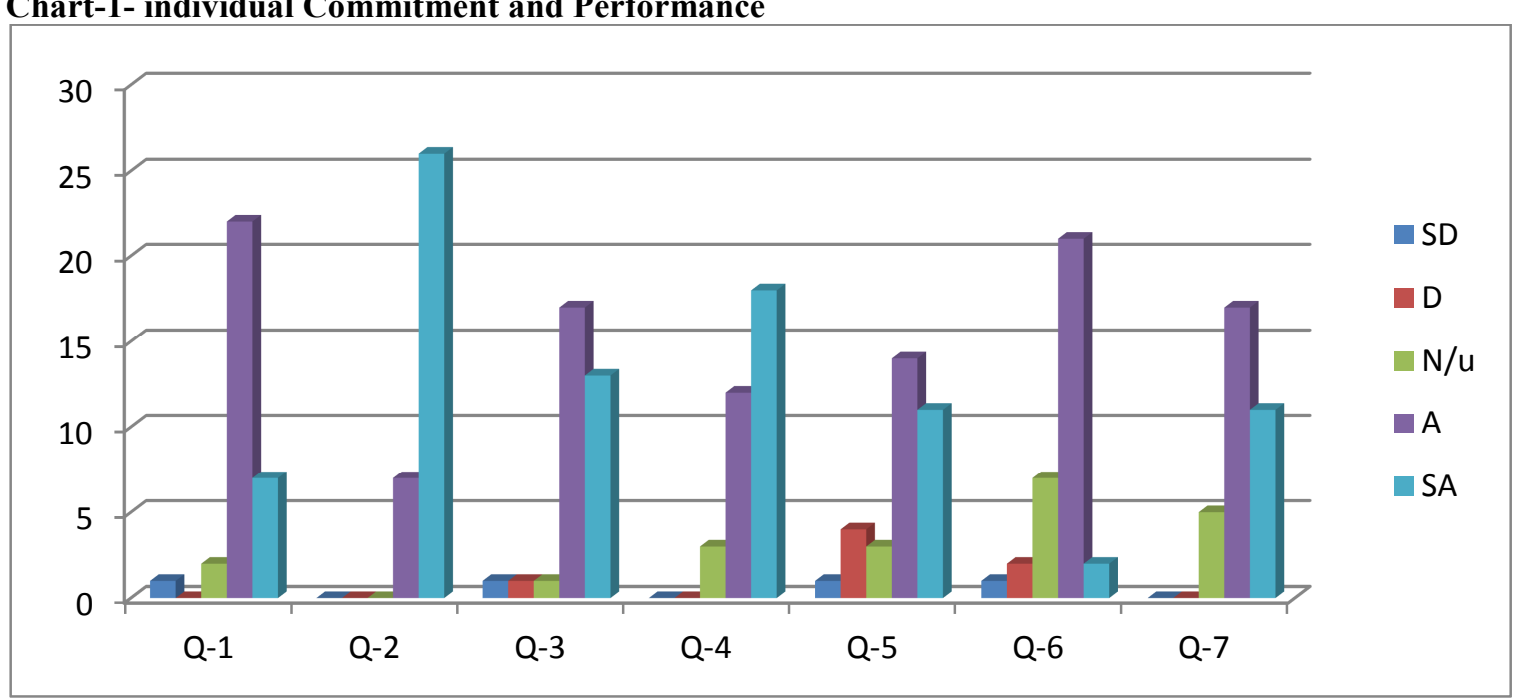

Interpretation: individual Commitment and Performance

In general, the responses were positive, signifying that most of the employees within these four organizations generally like their jobs, and believe they carry out their duties well. Most of the staff appears to take their jobs seriously and felt as though they were a vital part of the company's performance.

\section{2- Workplace Environment}

The second part of the study focused on the work environment as it applies to colleagues and the general feeling of teamwork in the organization. Majority of people prosper in an atmosphere that feels open and collaborative, such surroundings allows employees to be themselves and still work with others in a fruitful way. As most employees spend at least a quarter of their time at work within a week, the comfort level and a pleasing workplace is an essential factor.

Table-2- Workplace Environment

\begin{tabular}{|c|c|c|c|c|c|}
\hline \multirow[b]{2}{*}{ Workplace Environment } & \multicolumn{5}{|c|}{ Responses } \\
\hline & SD & $\mathbf{D}$ & $\mathbf{N} / \mathbf{u}$ & $\mathbf{A}$ & SA \\
\hline I am satisfied with my sense of belonging at work & 2 & 2 & 2 & 16 & 11 \\
\hline I feel like I am part of a team & 2 & 2 & 1 & 13 & 14 \\
\hline The employees work as a team to reach goals & 2 & 1 & 5 & 18 & 7 \\
\hline The employee morale is fairly high & 1 & 2 & 4 & 17 & 9 \\
\hline There is excellent communication within the organization & 3 & 6 & 5 & 15 & 4 \\
\hline Leaders inform staff on regular bases & 3 & 5 & 5 & 17 & 3 \\
\hline I feel at ease in my workplace & 2 & 1 & 2 & 19 & 9 \\
\hline
\end{tabular}




\section{Chart-2- Workplace Environment}

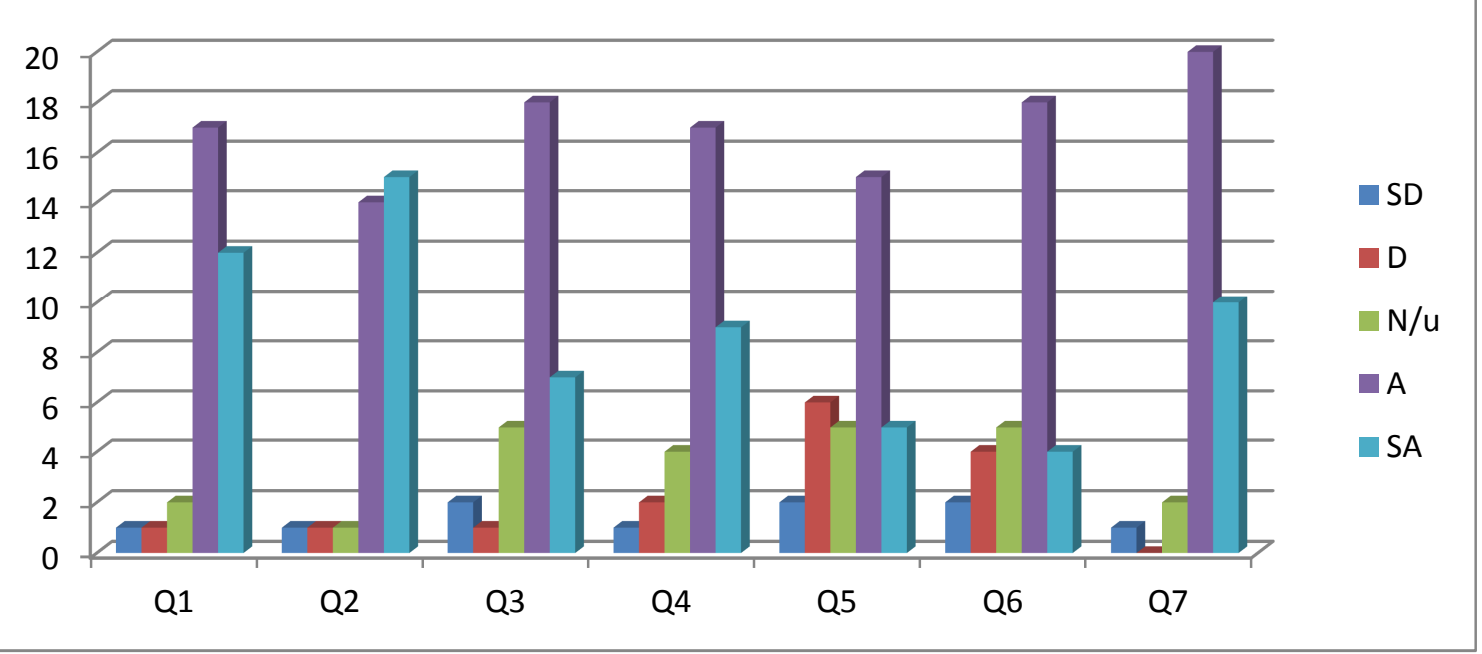

\section{Interpretation: Workplace Environment}

In this section there were more negative answers to the questions than the preceding section, predominantly in regard to the communication question. Also, in response to the question about leadership keeping employees informed, more employees disagreed than they had with previous questions. Responding neutrally to this set of questions exceeds first section as well.

\section{3- Recognition and Satisfaction}

Every employee likes and worthy of appreciation and deserve to be valued for their performance at work. When employees are told how good they perform, they frequently make every effort to do more; this indicates that recognition of staff is directly related to performance. The questions in this segment were intended to discover employees' feelings regarding their recognition and overall satisfaction levels.

Table-3- Recognition and Satisfaction

\begin{tabular}{|c|c|c|c|c|c|}
\hline \multirow[b]{2}{*}{ Recognition and Satisfaction } & \multicolumn{5}{|c|}{ Responses } \\
\hline & SD & $\mathbf{D}$ & $\mathbf{N} / \mathbf{u}$ & $\mathbf{A}$ & SA \\
\hline I feel I am recognized for my job performance & 3 & 2 & 8 & 17 & 3 \\
\hline It is essential to me that I am recognized & - & 1 & 4 & 13 & 15 \\
\hline Employees' hard work are rewarded & 4 & 10 & 10 & 7 & 2 \\
\hline I am aware of reward programs within the company & 2 & 9 & 8 & 12 & 2 \\
\hline I feel the recognition I receive is genuine & 3 & 3 & 9 & 15 & 3 \\
\hline Celebrations/events are a common occurrence & 7 & 9 & 11 & 5 & 1 \\
\hline I am pleased with my reimbursement & 4 & 4 & 11 & 13 & 1 \\
\hline
\end{tabular}

\section{Chart-3- Recognition and Satisfaction}

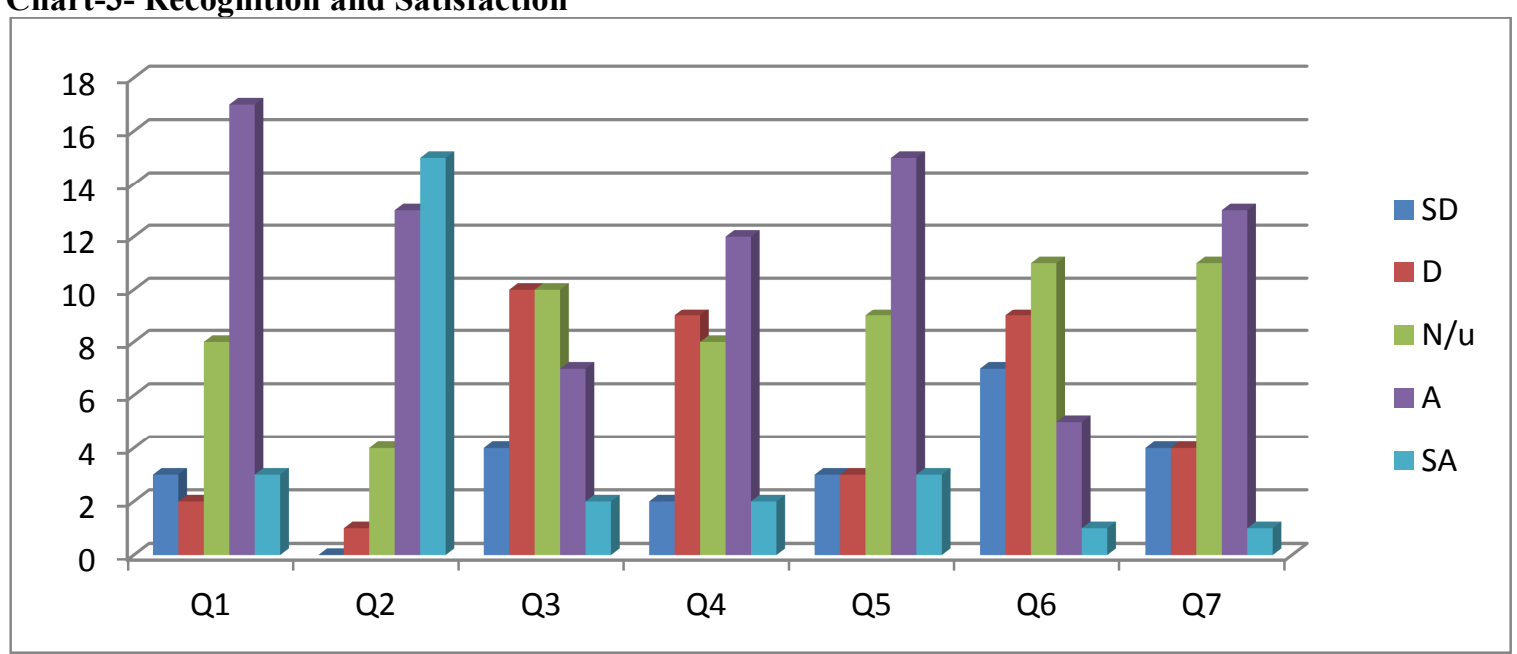




\section{Interpretation: Recognition and Satisfaction}

Answers in this section produced many more disagree answers than the previous two sections suggesting their individual contributions were not rewarded within the organization. Furthermore, nearly as many replied as neutral to the notion. Roughly twenty-four percent of the employees surveyed did not have the knowledge regarding reward programs established within the organization. A large number of employees responded that celebrations and/or events were not scheduled within their company very often. There were also many more neutral/undecided answers in this segment, which could suggest a number of things including uncertainty about the idea of recognition or perplexity about the definition of recognition.

\section{4- Relationship with Leadership}

The last section concentrates on leadership as one of the most essential factor in any organizational culture with many more questions than previously presented.

To get an idea of what kind of leadership exists within the organizations, the researcher provided an assortment of questions to the participants regarding their management teams.

Table-4- Relationship with Leadership

\begin{tabular}{|c|c|c|c|c|c|}
\hline \multirow[b]{2}{*}{ Relationship with Leadership } & \multicolumn{5}{|c|}{ Responses } \\
\hline & SD & $\mathbf{D}$ & $\mathbf{N} / \mathbf{u}$ & $\mathbf{A}$ & SA \\
\hline I feel leadership team cares about me as an individual & 19 & 9 & 2 & 2 & 1 \\
\hline leaders are supportive of my performance & 20 & 8 & 1 & 2 & 2 \\
\hline My ideas/suggestions are taken seriously & 18 & 5 & 8 & 2 & - \\
\hline leaders treat employees with dignity and respect & 19 & 8 & 4 & 2 & - \\
\hline Management regards each employee as important & 17 & 6 & 7 & 2 & 1 \\
\hline Leadership team has the respect of the employees & 13 & 9 & 7 & 2 & 2 \\
\hline Leadership team can be trusted & 17 & 11 & 2 & 2 & 1 \\
\hline I feel leaders would make personal sacrifices for the team & 17 & 6 & 4 & 3 & 3 \\
\hline Management includes themselves as part of the overall team & 15 & 11 & 3 & 1 & 3 \\
\hline Management works as hard as they expect employees to & 17 & 13 & 2 & - & 1 \\
\hline $\begin{array}{lcccc}\text { I feel comfortable approaching leadership team } & \text { with } \\
\text { concerns/questions }\end{array}$ & 14 & 12 & 4 & 2 & 1 \\
\hline Management works as a team to reach the same goals & 14 & 11 & 5 & 1 & 2 \\
\hline
\end{tabular}

Chart-4- Relationship with Leadership

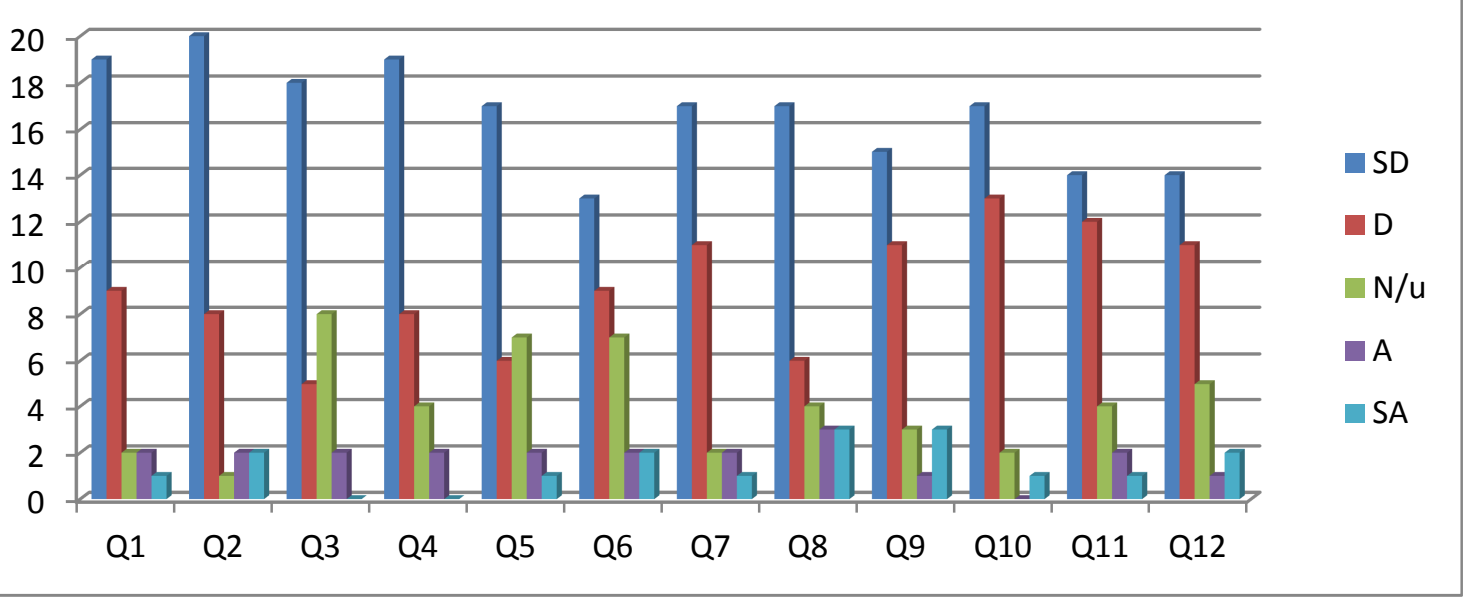

\section{Interpretation: Relationship with Leadership}

The responses for this part were mainly negative, the majority disagreed that leadership was part of the team, could be trusted, were supportive, treated employees with dignity and respect, cared about the employees, and that they work as hard as they expect the employees to. In general, the leadership within the organization appears to be disrespected by the staff. Of course, not all of the responses were negative; however, the overall results obtained through this climate assessment of companies were 
negative.

\section{Discussion}

As discussed before, there are several elements that contribute to the culture of an organization such as: leadership, employee satisfaction, workplace environment, and recognition and reward programs. These features establish the existence and health of the organization and any of these factors can lead to a decline and a decrease employee performance. Based on the outcome of the study, the researcher will present recommendations concerning potential areas of enhancement. These improvements may demonstrate to be advantageous to the overall wellbeing of the organizations.

\section{Limitations}

Even though significant information was obtained through this study, however, it is decisive to keep in mind that not all data can be supplied through the surveys. The purpose of the study was to achieve and understand the employees' view of their leadership and the environment in which they work in. The result of the study does not describe as to why the staff responded to the questions as they did.

- The questionnaire may have been understood in a different manner as the surveyor anticipated.

- The aim of the questions may also have been misunderstood by employees; therefore, they may perhaps have responded neutral/undecided $(\mathrm{N} / \mathrm{u})$.

- Some employees might have answered the questions untruthfully as they may have been concerned about confidentiality and anonymity of their responses.

There is a possibility that perhaps these limitations may have led to erroneous outcomes and interpretation

\section{Conclusions}

Surveyed Organizations were all involved a culture in which contains many elements including leadership, staff, workplace environment, and incentive and recognition programs.

In the surveyed organizations, employees answered that they cared about their jobs and carry out their tasks well. The individual dedication and performance of the first section of the survey scores were very high indicating the importance of employees' jobs and their value to the organizations. Nevertheless, it is not sufficient for the staff unless they are treated by the leadership with dignity and respect.

The survey shows that employees sense they are vital to the organization but do not feel that they are part of a well-built team. The research illustrates that organizations are in need of a better team work to make effort toward a common goal of the company.

Communication as a major factor in any organization also is in need of improvement; leadership must communicate relevant information to the staff in regards to corporate situation. This will add to employee ownership of their performance and satisfaction about their position in the company.

The survey indicates the major issues with lack of rewards and recognition in these organizations. Incentive, appreciation and respect along with good reward program would assist employees feel recognized and respected in which would add to team effort.

The last section was concerned with employee relationship with Leadership team as the result indicates the most negative. The result of this segment Indicates tension between the staff and management team that is fatal to any organization; moreover, causing disrespect and dissatisfaction with the company leading to low performance and increase turnover.

\section{Recommendations}

Based on the result of this survey, the researcher will recommend the following improvement that can help regional organizations enhance their operation and gain prosperity in the local community.

- Leaders to develop reward and recognition program through events to bring about unity among staff. According to Freiberg and Freiberg Celebrations can provide an opportunity for building relationships, give employees a sense of the organization's history, help people to look toward the future, celebrate milestones, reduce stress, inspire motivation and reenergize people, build self-confidence and remove fear, and can help mourn the losses associate with change (1996).

- Leaders to create unity through teamwork among workforce to put effort toward a common mission of the organization. Team work aids in better communication, positive impact on problem solving, positive effect on sense of commitment to the organization, job satisfaction and morale; it also improves performance and effectiveness.

- Leaders to develop a good communication system and evaluate the current information flow within their respective companies also to verify how much of the information that comes to them reach the employees. "Information is power": it equips people to do their jobs better (Freiberg \& Freiberg, $1996 \mathrm{p}$. 285). 
- Create a Leadership qualities that influence workforce performance include the ability to create vision, comprehend organizational culture, concentrate on performance improvement, and promote innovation. According to Buckingham and Coffman, leaders play a considerable part in persuading employee performance and an organization's culture; in fact, leaders are one of the most essential elements of an organization (2005 p.28).

- Leaders to establish and place comment/suggestion boxes in different area of the organization to obtain more information and identify areas of concern. This will allow leaders to make changes within the organization and stay proactive.

\section{References}

Alvesson, M. (2002). Understanding Organizational Culture. London: Sage.

Barney, J.B. (1991). Firm Resources and Sustained Competitive Advantage. Journal of Management, 1

(17): $99-120$

Branham, Leigh. (2001) Keeping the People Who Keep You in Business. New York, NY: American Management Association.

Branham, Leigh. (2005) The 7 Hidden Reasons Employees Leave. New Yark, NY: American Management Association.

Buckingham, Marcus \& Coffman, Curt. (2005) First, Break All the Rules. Great Britain: Pocket Books Simon \& Schuster UK Ltd.

Cascio, W. F. (2006). Managing Human Resources: Productivity, Quality of Life, Profits. McGraw-Hill Irwin.

Christine Kane-Urrabazo: Management's role in shaping organizational culture. Journal of Nursing Management 2006, 14:188-194.

Collins, Jim. (2001) Good to Great. New York, NY: HarperCollins Publishers Inc.

Freiberg, Kevin \& Jackie. (1996) Nuts! Southwest Airlines' Crazy Recipe for Business \& Personal Success. NY, NY Broadway Books.

Gallagher, Richard S. (2003) The Soul of an Organization. United States of America: Dearborn Trade Publishing. Gostick, Adrian \& Elton, Chester. (2001) Managing with Carrots. Salt Lake City, UT: O.C. Tanner Recognition Company

Kotter, John P. \& Heskett, James L. (1992) Corporate Culture and Performance. New York, NY: The Free Press. Kouzes, James \& Posner, Barry. (2002) The Leadership Challenge. (3rd ed.) San Francisco, CA: Jossey-Boss. Martin, J. (2002). Organizational Culture: Mapping the Terrain. London: Sage.

Podmoroff, Dianna. (2005) 365 Ways to Motivate and Reward You Employees Every Day-With Little or No Money. Ocala, FL: Atlantic Publishing Group, Inc.

Schein, Edgar. (2004) Organizational Culture and Leadership. (3rd ed.) San Francisco, CA: Jossey-Boss.

Schein, Edgar. (1999) The Corporate Culture Survival Guide. San Francisco, CA: JosseyBoss.

Stannack, P. (1996). Perspective on Employees Performance. Management Research News, 119(4/5), 38-40.

Tuckman, Bruce W. (1965) Developmental Sequence in Small Groups. Pyschological Bulletin. 63 (6) $384-399$

Wilderom, C.P.M., Glunk, U. \& Maslowski, R. (2000) Organizational Culture as a Predictor of Organizational Performance. In: N. Ashkanasy, C.P.M. Wilderom \& M.F. Petersen (eds.), Handbook of Organizational Culture \& Climate, (pp. 193-209). Thousand Oaks, CA: Sage Publications.

Wingfield, Barb \& Bury, Janice. (2001) Retaining your Employees. Boston, MA: Thomson Course Technology. 
The IISTE is a pioneer in the Open-Access hosting service and academic event management. The aim of the firm is Accelerating Global Knowledge Sharing.

More information about the firm can be found on the homepage:

http://www.iiste.org

\section{CALL FOR JOURNAL PAPERS}

There are more than 30 peer-reviewed academic journals hosted under the hosting platform.

Prospective authors of journals can find the submission instruction on the following page: http://www.iiste.org/journals/ All the journals articles are available online to the readers all over the world without financial, legal, or technical barriers other than those inseparable from gaining access to the internet itself. Paper version of the journals is also available upon request of readers and authors.

\section{MORE RESOURCES}

Book publication information: http://www.iiste.org/book/

\section{IISTE Knowledge Sharing Partners}

EBSCO, Index Copernicus, Ulrich's Periodicals Directory, JournalTOCS, PKP Open Archives Harvester, Bielefeld Academic Search Engine, Elektronische Zeitschriftenbibliothek EZB, Open J-Gate, OCLC WorldCat, Universe Digtial Library, NewJour, Google Scholar

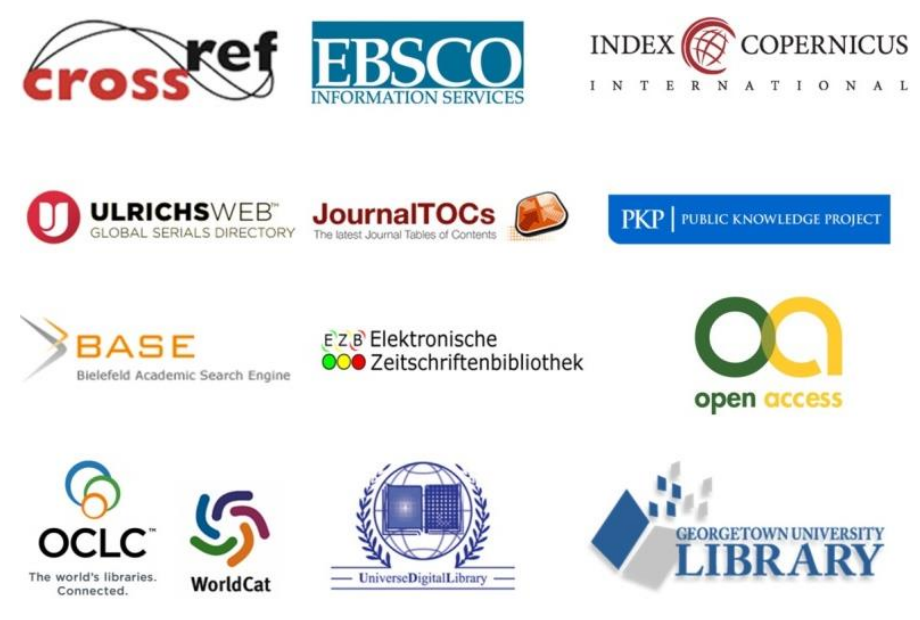

